\title{
The Latin American Bibliographical Activities of the Library of Congress, with Hints for Future Developments in This Field
}

Mr. Hanke, chief, Hispanic Foundation, Library of Congress, read this paper at a meeting of the Reference Librarians Section of the Association of College and Reference Libraries, December 30, I94I.

$\mathrm{T}$

He Library of Congress at this moment bears a marked resemblance, insofar as its Latin American bibliographical activities are concerned, to a boa constrictor who has swallowed a sheep and is thoroughly engaged in labor. For during the last two years the Library has started work on several major activities in this field which are now absorbing much of our time and attention but which will not yield published results until some time hence. Most of the projects are being supported by grants made, on a temporary basis, by Congress through the Inter-Departmental Committee on Cooperation with the Other American Republics, by the Rockefeller Foundation, or by the Coordinator of Inter-American Affairs. Many of them could not be profitably carried on now, however, were it not for the fact that the Library has been concerned with Latin America for many years and has made regular attempts to build up its collections.

\section{Music}

Almost everything in the field of music is still to be done. No great collections exist, few bibliographies have been prepared, and the number of trained specialists is small. The appointment last year of Gilbert Chase as the Latin American assistant in the Music Division was a real step forward and has already resulted in the compilation of a mimeographed "Bibliography of Latin American Folk Music," comprising more than a thousand annotated items. In order to aid educators and students who do not read Spanish or Portuguese, Mr. Chase is now compiling a "List of References in English on Latin American Music" and already some three hundred have been collected. Mr. Chase also compiled a "Partial List of Latin American Music Available in the United States, with a Supplementary List of Books and a Selective List of Phonograph Records," which was published in mimeograph form by the Music Division of the Pan American Union last March.

The most important bibliographical tool under way, however, is the "Guide to Latin American Music" which Mr. Chase is now preparing and hopes to have ready 
within two years. It is expected that this "Guide" will be a basic reference tool in this relatively neglected field by providing information on the music, the literature about the music, and on musicians and musical organizations.

\section{Documents Division}

Probably more books, periodicals, and pamphlets are published by the various Latin American governments than by all their private publishers put together. These publications are rarely brought under bibliographical control by the governments themselves and the great mass of the publications which pour forth become known to few people and few libraries have reasonably complete files. The importance, therefore, of the "Guide to the Official Publications of Latin American Governments" now being compiled by James B. Childs with various assistants can readily be appreciated. It is planned to include the following information : First, the correct name of the bureau or department as determined by both statute and usage. Second, reference to the legal antecedents, such as the law or decree of its creation, the law or decree regulating its functions and organization, and other legal measures vitally affecting it. This legal data would facilitate further investigation as to more detailed information regarding its functions and organization. Third, a description of the publications issued and explanation of their contents if not already clarified by the title. Mr. Childs' publications in this field are already well known and in as much as the Library is an official depository of the publications of foreign governments, our collections are reasonably complete. One of the valuable by-products of the "Guide" will be to locate our weaknesses.
This work is necessarily slow but a draft of the Paraguayan section has been completed and will soon be sent to the government of Paraguay for suggestions and criticisms, a procedure to be followed with all sections of the "Guide." Work is already in progress on the publications of Bolivia, Chile, and Colombia.

\section{Law Library}

A large part of the intellectual resources of Latin America has been devoted to law and many of her most eminent figures today have had legal training. It is not surprising, therefore, that the legal literature of Latin America is both voluminous and important. A quarter of a century ago the Library published a Guide to the Law of Argentina, Brazil, and Chile by Edwin M. Borchard which is still one of the few standard reference works in the field. John T. Vance, present law librarian, has continued this interest in Latin American law and now has Crawford Bishop at work on a "Guide to the Law and Legal Literature of Nine American Republics." Introductory chapters on each of the nine countries have been written, outlining their legal and constitutional history from their independence until today, and particular attention is being given to the study of legal periodicals. When completed, this "Guide" will provide the basic bibliographical information on the law of these countries.

\section{Hispanic Foundation}

The following projects are under way in the Hispanic Foundation, the division of the Library specifically devoted to Hispanic culture, which was opened in 1939.

I. "Guide to Latin American Periodicals Currently Received in the Library of Congress." Periodicals in Latin Amer- 
ica are difficult to follow because they are established, stopped, suspended, or just disappear with astonishing rapidity. Even periodicals published about Latin America in this country have these characteristicswitness the recent death of the InterAmerican Quarterly which for the last three years has been a great boon to librarians who had to recommend a review in English on Latin America. To provide a standard guide in this difficult field the Hispanic Foundation has prepared a tentative list of about nine hundred items. This preliminary edition, which is not for distribution, contains the following information on each item : title of the periodical, initial date of publication, number of issues per year, method of enumeration, name of the director or editor, place of publication, name of the publisher, the Library of Congress classification number and card number, any information which has been found concerning the history of the publication, its changes in title, and periods of suspension. The final edition of the "Guide" will appear later in printed form, after the necessary revisions and changes have been made, and will include all the information given in the preliminary version, together with a brief paragraph describing and evaluating each periodical and bibliography listed. Those items which are considered important according to the judgment of the various editors of the Handbook of Latin American Studies, who are specialists in the various fields, will be indicated by a star. The mortality rate of the editors of this "Guide" has been high. The first and second incumbents, Murray Wise and Alexander Marchant, joined the State Department staff in quick succession, and Charmion Shelby, the third editor, will be responsible for the final edition.

\section{Materials in Fine Arts}

2. The "Guide to Materials in the Fine Arts in Brazil and Spanish America" is now well under way, directed by Robert C. Smith, with the assistance of Elizabeth Wilder. It has now been about half completed and will consist of the following items: ( I ) A selected bibliography of published books and articles pertaining to the fine arts in Brazil and Spanish America from the beginning of the colonial period to the present, with informative and evaluative notes on each item; (2) A selected list of periodicals devoted to the fine arts in Brazil and Spanish America; (3) A list of the public museums and private collections of art, history, and archeology in Brazil and Spanish America with a description of their buildings, collections, publications, and personnel ; (4) A list of the government agencies, professional societies, and principal dealers and photographers; (5) A list of the art historians interested in the field, with information on the age, position, field of research, and principal publications, and a discussion of the teaching of the subject in the universities and schools of the American republics.

In order to secure fresh and detailed information for the "Guide" Mr. Smith has visited Mexico and Central America and Miss Wilder has made an extensive trip in South America. Another related activity in this field is the "Archive of Hispanic Culture" now being built up by Mr. Smith. The field of Spanish American and Brazilian art is one of the most neglected in the general history of the fine arts. We know relatively little about the artistic styles, the monuments, and the artists of each Latin American country from the beginning of the colonial period 
to the present day. It is true that in the case of Mexico a few general books illustrating the principal monuments of architecture and painting have been published but sculpture has been neglected. And in the case of the art of the other nations there is neither a general history, special monograph, nor guidebook which adequately illustrates even a small portion of the existing monuments. Nor do separate photographs exist in this country. In the great photographic archives already established at Harvard and New York universities and at the Frick Art Reference Library, there is almost no material on Brazil or Spanish America.

This archive will include photographs and relevant biographical information, will serve as a primary reference collection for scholars engaged in research in this field and for others who will visit it for purposes of comparison, for the historian wishing to illustrate his publication with the best reproductions available, and in the field of the minor arts for the collector.

\section{Social Science and Humanistic Studies}

3. A third publication now in preparation is the "Record of Investigations in the Field of Latin American Social Science and Humanistic Studies." The scholars of the Americas, where most of these investigations are being pursued today, are not banded together in as well-knit professional associations as were European scholars before the war. For example there is no up-to-date or satisfactory directory of learned societies in Brazil and Spanish America. There is no directory of scholars in these countries. Professional communication is difficult-often impossible. Often scholars in Latin America do not realize how many studies are being prepared in this country on their own culture.
The "Record of Investigations in Progress" is designed to provide the following basic information on investigators in this country at work on some phase of the Latin American social science or humanistic studies: (I) Name, age, and permanent mailing address of the investigator. (2) Principal field of research and a list of principal publications in their field. (3) Title of investigation now in progress and number of years it has been under way.

It is pleasant to turn away from all these projected publications which are now merely in preparation, to mention bibliographies which are now ready for distribution or which will shortly be ready:

I. The long-awaited C. K. Jones "Bibliography of Latin American Bibliographies" is now in galley proof. This bibliography is a compilation of some 2500 titles of books and articles, in which are included collective biographies, histories of literature, anthologies and bio-bibliographical notes, and some general and miscellaneous works of frequent use for reference purposes, encyclopedias, anuarios, almanacs, and others of like character. Descriptive and evaluative notes are provided for many of the items and it is expected that this work will become the basic reference volume for all students engaged in Latin American studies and for all librarians and catalogers throughout the Americas.

\section{Handbook of Studies}

2. Handbook of Latin American Studies. The sixth annual number of this bibliography of the important publications of the previous year on anthropology, archives, art, economics, education, folklore, geography, government, history, international relations, law, language and litera- 
ture, libraries, music, and philosophy is now in page proof and will soon appear in book form. The Handbook is published under the auspices of the Committee on Latin American Studies of the American Council of Learned Societies and edited by Miron Burgin of the Hispanic Foundation staff with the assistance of thirty-eight section editors.

3. Another publication of this same committee, edited by Madaline Nichols of the Hispanic Foundation staff, is the Bibliographical Guide to Materials on American Spanish. This Guide lists the outstanding studies on the Spanish language in the several Spanish American countries. It includes a brief historical account of the growth of an American Spanish; a special section on the work of the American language academies and philological institutes; and approximately twelve hundred annotated entries, covering general studies of the language of each country, dictionaries and vocabularies of local terms, words borrowed from other languages, geographical nomenclature, and flora and fauna.

This then is the story of Latin American bibliographical activity now in progress at the Library of Congress. Before passing into the dangerous realm of conjecture and prophecy-where certain suggestions will be made as to bibliographies that need to be prepared and certain guesses will be hazarded as to future development-I should like to cite one other activity of the Hispanic Foundation which may be of interest to those of you who have a special concern with the technical processes of a library. Being a new development and having many intimate connections with other divisions of the $\mathrm{Li}$ brary we decided to have technical studies made of various problems which had pre- sented themselves to us. We were fortunate enough to secure the services of Anita M. Ker (now Mrs. Duncan Johnson) formerly of the Catalog Division of the Library, and during the course of about a year she made investigations and reports on the following topics:

I. A study of the practicability of the establishment of a union catalog of the Hispanic material contained in all District of Columbia libraries.

2. The compilation of a guide to Hispanic material in the libraries of the District of Columbia.

3. A report on the feasibility of having all the Hispanic material in the Library of Congress represented in a general Hispanic catalog.

4. A study of the possibility of engaging in extensive analysis of Hispanic periodicals.

5. A selection and listing of some 160 titles of Hispanic periodicals suggested for analyzation. This selection was made with the aid of various specialists and leaders in divers fields of Hispanic culture and thought.

6. A report setting forth in detail the major difficulties which exist in the present method of control over Hispanic periodicals received and housed by the Library of Congress. Remedial measures are suggested in this report.

These reports are all fairly detailed and technical but information on any of them may be obtained by writing to the Hispanic Foundation.

\section{Other Activities and Bibliographies}

There are many other activities and bibliographies that need to be considered and which doubtless will be carried out in the fullness of time. Some of the more important ones already discussed in the Library-and which have already been turned down by those persons holding the moneybags-are :

I. "Guide to the Manuscripts Bearing on Latin America in the Library of Con- 
gress." The Manuscripts Division has thousands of pages of manuscripts and transcripts on Latin America but no suitable guide exists.

2. "Guide to Current Statistical Sources on Latin America." Statistical information on education, trade, politics, etc., of Latin America comes out in many different kinds of publications in many countries, but no guide to them has been prepared to make it easy for the student who would use these widely scattered sources.

3. "Guide to Government Departments of Latin America." As our relations with Latin America are solidified, and when the Childs" "Guide to the Official Publications of Latin America" is completed, the need for this "Guide" will be felt and money will be secured to prepare it. The importance of government agencies in all cultural undertakings in Latin America is such that libraries perforce must have some sort of assistance to enable them to deal effectively with the many agencies.

4. Project to microfilm manuscripts in Latin American libraries. The Library of Congress project by which hundreds of thousands of pages of manuscript material on United States history in European archives is too well known to require detailed description. This project was made possible, of course, by the previous preparation of excellent guides to the pertinent material in these archives by the Carnegie Institution of Washington. No similar guides exist to the archives of Latin America, but even so, much valuable material could be brought to this country if funds were available to embark on this project.

\section{Future Developments}

In conclusion, if one may enter the dangerous field of conjecture and prophecyattention should be directed in the future toward the following three general developments in this field which are important -so important that, somehow or other, the obstacles must be removed or surmounted :

\section{The building up of adequate collec-} tions of Latin American books in our college and public libraries. Many courses are being offered on Latin America and much general interest has been aroused on inter-American relations but more can and should be done to improve the existing book collections in Portuguese and Spanish. Book publishing in Buenos Aires, Santiago, Mexico City, and Havana has greatly developed during the past five years and a great variety of inexpensive books is now available for purchase. The section on "Latin American Book Catalogs" of the Handbook of Latin American Studies provides an annual statement on available material.

II. The preparation of guides to Latin American material in our libraries and archives. This country has great resources of printed and manuscript material on Latin America but much remains to be done before it is adequately known or cataloged. Important guides to some of the collections now exist but the field is large and will require years of cultivation by librarians and archivists.

III. The working out of a national system for the use of research materials in this country bearing on Latin America. 